\title{
SISTEMA DE INFORMAÇÃO GEOGRÁFICA APLICADO NO DIAGNÓSTICO DO USO DA TERRA DA BACIA HIDROGRÁFICA DO CÓRREGO SÃO CAETANO - BOTUCATU (SP)
}

\author{
Gabriel Rondina Pupo da Silveira ${ }^{1}$
}

Sérgio Campos ${ }^{2}$

Yara Manfrin Garcia ${ }^{3}$

\begin{abstract}
RESUMO
O trabalho visou obter o uso do solo da bacia hidrográfica do Córrego São Caetano - Botucatu (SP), através de imagem de satélite. As bases cartográficas foram: carta planialtimétrica em formato digital (IBGE) utilizada no georreferenciamento, e imagem de satélite. O Sistema de Informação Geográfica (SIG) - IDRISI Selva foi utilizado para realizar o georreferenciamento da imagem e confecção do mapa temático final. No software CAD - CartaLinx foi realizada a delimitação da área em estudo e levantamento dos elementos (limite, rede de drenagem e áreas de uso e cobertura da terra). $\mathrm{O}$ uso da terra da bacia mostrou que a pastagem foi a classe de maior predominância, ocupando $34,51 \%$ $(1117,94 \mathrm{ha})$ da área total, sendo o restante ocupado por área urbana $(692,19 \mathrm{ha})$, mata $(809,79 \mathrm{ha})$, culturas $(599,96 \mathrm{ha})$ e uma parte bem pequena de reflorestamento $(19,53 \mathrm{ha})$. A utilização de técnicas de sensoriamento remoto e de geoprocessamento foram muito satisfatórias na realização do presente
\end{abstract}

trabalho. Tecnologias devem ser cada vez mais utilizadas em trabalhos agrícolas e ambientais, pelo fato de ferramentas tecnológicas, como o Sistema de Informação Geográfica (SIG), apresentarem rapidez, eficácia e resultados confiáveis, ajudando no aumento da sustentabilidade.

PALAVRAS-CHAVE: Geotecnologia. Uso e Ocupação do Solo. Planejamento Ambiental.

\footnotetext{
${ }^{1}$ Mestrando no Programa de Pós Graduação em Agronomia / Energia na Agricultura - FCA/UNESP/ Botucatu/SP. E-mail: gabrielrondina@hotmail.com.

${ }_{2}^{2}$ Prof. Titular do Departamento de Engenharia Rural, FCA/UNESP/Botucatu/SP. E-mail: seca@fca.unesp.br.

${ }^{3}$ Doutoranda no Programa de Pós Graduação em Agronomia / Energia na Agricultura - FCA/UNESP/ Botucatu/SP. E-mail: yaramanfrin@hotmail.com
} 


\title{
GEOGRAPHIC INFORMATION SYSTEMS APPLIED IN THE DIAGNOSIS OF LAND USE OF WATERSHED STREAM SÃO CAETANO - BOTUCATU (SP)
}

\begin{abstract}
The study aimed to obtain the land use of the watershed Stream São Caetano - Botucatu (SP), through the satellite image. The cartographic databases were: planialtimetric letter in digital format (IBGE) used in georeferencing, and satellite image. Geographic Information Systems (GIS) -IDRISI Selva was use to perform the image georeferencing and to do the final thematic map. In the software CAD - CartaLinx, it was performed the delimitation of the area under study (boundary, drainage network and areas of use and coverage). The land use of the watershed showed that pasture was the class which occupied most of the area, with 34.51\% (1117,94 ha), the remainder of the area was urban $(692,19 \mathrm{ha})$, forests $(809,79 \mathrm{ha})$, cultures $(599,96 \mathrm{ha})$ and a very small part of reforestation (19,53ha). The use of remote sensing and geoprocessing were very satisfactory in the present work. Technologies must be increasingly used in agricultural and environmental studies, because technological tools, such as Geographic Information System (GIS), present speed, efficiency, reliable results, helping in increasing sustainability.
\end{abstract}

KEY-WORDS: Geotechnology. Soil use. Environmental Planning

\section{SISTEMAS DE INFORMACIÓN GEOGRÁFICA APLICADO EN EL DIAGNÓSTICO DE LA TIERRA DE LAS CUENCAS DEL ARROYO SÃO CAETANO - BOTUCATU (SP)}

\section{RESUMEN}

El objetivo del estudio fue obtener el uso del suelo de la cuenca Riachuelo São Caetano - Botucatu (SP), a través de imágenes de satélite. Las bases de datos cartográficos fueron: carta planialtimétrico en formato digital (IBGE) utilizado en la georreferenciación, además de la imagen de satélite. El Sistemas de Información Geográfica (SIG) IDRISI Selva se utilizó para la georreferenciación de la imagen, y la realización del mapa temático final. En el software CAD - CartaLinx se han realizado la delimitación de la zona de estudio y peritaje de los elementos (límite, red de drenaje y áreas de uso y cobertura de la tierra). El uso del suelo de la cuenca mostraba que el pastoreo era la clase predominante, ocupando $34,51 \%(1117,94 \mathrm{ha})$ de la superficie total; el resto de la zona ocupada por el área urbana $(692,19 \mathrm{ha})$, mata $(809,79 \mathrm{ha})$, culturas $(599,96 \mathrm{ha})$ y una parte muy pequeña de reforestación $(19,53 \mathrm{ha})$. El uso de la teledetección y los SIG son muy satisfactorios en el presente trabajo. Tecnologías deben utilizarse cada vez más en estudios agrícolas y ambientales, debido a las herramientas tecnológicas, como el Sistema de Información Geográfica (SIG) proporcionan resultados rápidos, eficaces y fiables, lo que ayuda en el aumento de la sostenibilidad.

PALABRAS CLAVE: Geotecnología. Uso y Ocupación. Preservación del Medio Ambiente.

\section{INTRODUÇÃO}

A degradação desenfreada dos recursos naturais nos dias de hoje é um processo que deve ser analisado com eficiência e rapidez. Os solos, por exemplo, 
vêm sofrendo uma constante e crescente degradação, em função da preservação e uso inadequados (BUCENE, 2002).

A substituição da cobertura original do solo por culturas agrícolas, aliada a práticas de manejo inadequadas, altera, entre outras coisas, as relações entre escoamento superficial e infiltração da água das chuvas, resultando em erosão do solo e carreamento de quantidades acima do normal de sedimentos aos canais de drenagem. Esse fenômeno é responsável pela aceleração do processo de assoreamento dos canais, além de alterar as características físicas e químicas da água pela presença dos sedimentos, material orgânico, nutrientes e outros elementos e compostos químicos, provenientes principalmente de defensivos agrícolas e fertilizantes, encarecendo os processos de captação e tratamento da água para consumo humano (VETTORAZZI, 2006).

A opção por uma bacia hidrográfica como local de estudo deve-se ao fato de ser esta uma unidade onde se tem diferentes características, desde regiões altas, onde normalmente estão localizadas as nascentes dos riachos e córregos, áreas de encostas, onde as águas correm com maior velocidade, e finalmente, as áreas de baixadas, onde normalmente são observadas as consequências do manejo inadequado feito nas altitudes mais elevadas.

O sensoriamento remoto é a ciência e a arte de se obter informações sobre um objeto, área ou fenômeno, através da análise de dados coletados por aparelhos denominados sensores (NOVO, 2008).

Para Garcia (1982), o sensoriamento remoto pode ser definido como a deteç̧ão da natureza de um objeto sem que haja contato físico, em que aviões e satélites são as plataformas mais comuns. $O$ termo sensoriamento remoto é restrito aos métodos que utilizam a energia eletromagnética na detecção e medida das características de objetos, incluindo-se aqui as energias relativas à luz, calor e ondas de rádio.

Rocha (2007) afirmou que a principal contribuição do Sensoriamento Remoto surgiu com as primeiras imagens orbitais do Planeta Terra. Desde então, o homem tem verificado uma grande degradação do meio ambiente terrestre, provocado por uma visão consumidora e descartável dos recursos naturais, como se fossem 
inesgotáveis, poluindo o solo, a água e o ar, e deixando uma perspectiva negativa para as gerações futuras. Esta visão holística contribui muito para uma mudança de paradigma conhecida como desenvolvimento sustentável.

A identificação e classificação do uso do solo são fundamentais no conhecimento do ambiente, assim como no desenvolvimento de técnicas voltadas para a obtenção e manutenção dessas informações. O conhecimento da distribuição espacial das várias formas de ocupação do espaço necessita de informações detalhadas, que possam ser obtidas com grande periodicidade, devido ao caráter extremamente dinâmico desse ambiente (FORESTI e HAMBURGER, 1995 apud BITTENCOURT et al., 2006).

A aplicação da tecnologia de Sistema de Informação Geográfica (SIG) facilita a maneira de como o uso do solo pode ser monitorado, pois técnicas relativamente simples podem fornecer informações que permitem a avaliação pontual e temporal, reparação e readequação dos usos, a um custo aceitável. Uma questão importante na adoção das técnicas de SIG para o planejamento do uso do solo é a atividade agrícola (PELEGRIN, 2001).

As geotecnologias constituem o conjunto de tecnologias que nos permitem a realização de coleta de dados, processamento, além da análise da informação georreferenciadas, e consequentemente favorece a tomada de decisões.

O uso dessas geotecnologias nos permite fazer uma análise integrada do ambiente, de forma a entender como questões relacionadas às alterações ambientais se comporta no espaço, sendo este um dos pontos fortes que permitem com que o ambiente seja estudado em parte, e entendido como um todo (PIRES et al., 2012).

O presente trabalho objetivou na identificação da ocupação do solo presente na bacia hidrográfica do Córrego São Caetano - Botucatu (SP), por meio da utilização de técnicas de geoprocessamento conseguidas a partir de software SIG (Sistema de Informação Geográfica), possibilitando a identificação e análise do uso da terra da bacia hidrográfica, dados estes necessários para planejamentos ambientais, servindo como base para viabilização das irregularidades nessas áreas, além de contribuir para a determinação do melhor uso e ocupação do solo desta e de futuras áreas em estudo. 


\section{MATERIAIS E MÉTODOS}

A bacia hidrográfica do Córrego São Caetano encontra-se situada no município de Botucatu (SP), é definida pelas coordenadas geográficas: latitude $22^{\circ} 46^{\prime} 21^{\prime \prime}$ a $22^{\circ}$ $52^{\prime} 32^{\prime \prime}$ S e longitudes $48^{\circ} 26^{\prime} 25^{\prime \prime}$ a $48^{\circ} 29^{\prime} 27^{\prime \prime}$ W Gr., e apresenta uma área de 3239.41ha, conforme mostrado na Figura 1.

Figura 1 - Localização da bacia hidrográfica do Córrego São Caetano no município de Botucatu, Estado de São Paulo.

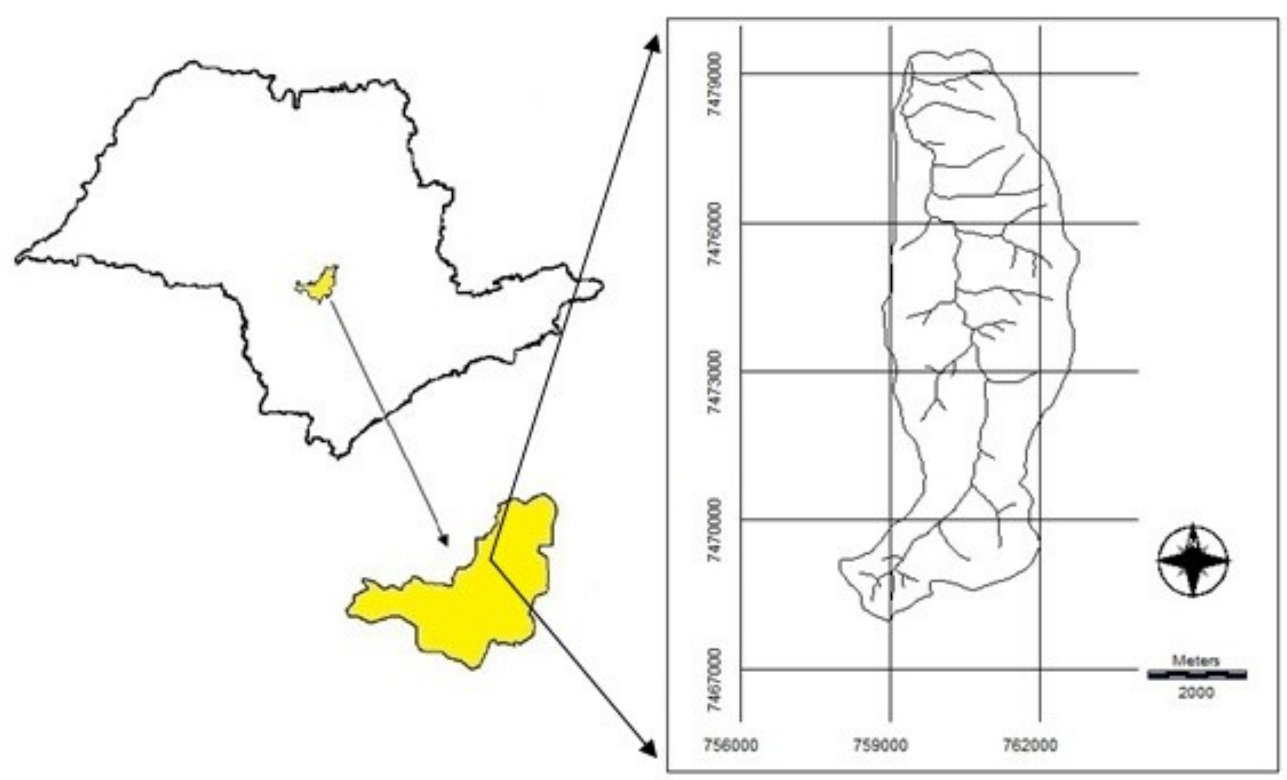

O clima predominante do município, classificado segundo o sistema Köppen é do tipo Cwa - Clima Mesotérmico de Inverno Seco - em que a temperatura do mês mais frio é inferior a $18^{\circ} \mathrm{C}$ e do mês mais quente ultrapassa os $22^{\circ} \mathrm{C}$.

De acordo com Souza (2012), a nascente do Córrego São Caetano situa-se no distrito industrial I, do Município de Botucatu (SP), que segundo Silva (1999), sua sede tem as seguintes coordenadas geográficas: $22^{\circ} 52^{\prime} \mathrm{S}$ e $48^{\circ} 26^{\prime} \mathrm{WGr}$.

Ainda, o mesmo autor citado anteriormente ressalta que, o Córrego São Caetano demonstra uma importância regional, por abastecer de água o setor agrícola, na dessedentação de animais, uso doméstico, recreação e lazer. Afluente do Córrego 
Fundo e do rio Araquá, ambos deságuam no rio Capivara - o mais importante afluente à margem esquerda da bacia do Médio Tietê.

Os pontos de controle (coordenadas) para o georreferenciamento, e os pontos de máxima altitude para digitalização do limite da bacia hidrográfica tiveram como base a Carta Planialtimétrica em formato digital, editada pelo Instituto Brasileiro de Geografia e Estatística - IBGE (1969), folha de Botucatu (SF-22-R-IV-3), em escala $1: 50000$.

Utilizou-se imagem de satélite digital, das bandas 3, 4 e 5 do sensor Thematic Mapper do LANDSAT - 5, da órbita 220, ponto 76, quadrante A, passagem de 2011 , escala 1:50000.

O processamento dos dados foi realizado em um microcomputador Processador Intel Inside CORE i7, 1,80 GHz, com sistema operacional de 64 bits, HD 1TB, 8GB de memória RAM, com saída para impressora a jato de tinta HP Deskjet 695 C. Para entrada das informações analógicas como limite da bacia hidrográfica e as áreas de cobertura vegetal foram utilizados o Scanner Genius Vivid Pro II.

O Sistema de Informações Geográficas - IDRISI Selva foi usado no processamento das informações georreferenciadas, na conversão dos dados vetoriais em imagem raster e na elaboração do mapa final do uso da terra.

O software CartaLinx foi utilizado na digitalização do limite da bacia hidrográfica, da rede de drenagem e das áreas de cobertura vegetal, obtidas através de imagens de satélite.

A delimitação de uma bacia hidrográfica é dada pelas linhas divisoras de água que demarcam seu contorno. Estas linhas são definidas pela conformação das curvas de nível existentes nas cartas planialtimétricas, e ligam os pontos mais elevados da região em torno da drenagem (ARGENTO e CRUZ, 1996).

O contorno da área da bacia hidrográfica do Córrego São Caetano - Botucatu (SP) foi realizado através da carta planialtimétrica editada pelo Instituto Brasileiro de Geografia e Estatística - IBGE em 1969, folha de Botucatu (SF-22-R-IV-3), escala 1:50000, segundo os pontos mais elevados em torno da drenagem, tendo-se como base a definição de Rocha (1991), para bacia hidrográfica. 
Primeiramente foi importado para o IDRISI, em formato vetorial, o arquivo TIFF que contêm a carta planialtimétrica. Esse arquivo foi georreferenciado, sendo posteriormente, com o auxílio do software CartaLinx feito a delimitação da área de estudo.

Inicialmente, foi elaborada uma composição colorida com a combinação das bandas 3 , 4 e 5, obtida a partir da imagem de satélite digital, bandas 3 , 4 e 5 do sensor Thematic Mapper do LANDSAT - 5, da órbita 220, ponto 76, quadrante A, passagem de 2011, escala 1:50000, pois esta apresenta uma boa discriminação visual dos alvos, possibilitando a identificação dos padrões de uso da terra de maneira lógica. Esta composição apresenta os corpos d'água em tons azulados, as florestas e outras formas de vegetações em tons esverdeados e os solos expostos em tons avermelhados.

Para a composição, foi realizado o processo de composição da imagem RGB (Red/Green/Blue), utilizando-se da função Composite do menu Display do IDRISI.

A seguir, foi realizado o georeferenciamento da composição, utilizando-se para isso do módulo Reformat/Resample do SIG-IDRISI, sendo os pontos de controle obtidos das cartas planialtimétricas do IBGE, referente ao município de Botucatu.

Após o georreferenciamento, foi feito o corte, extraindo-se apenas a área da bacia. Para o georreferenciamento, também foi utilizado o sistema de coordenadas planas, projeção UTM, datum Córrego Alegre. Porém, foi utilizado dois arquivos de pontos de controle, sendo o primeiro da imagem de satélite e o outro, da carta topográfica de Botucatu, que já estava georreferenciada pela etapa anterior. Desta forma, foram determinadas as coordenadas de cada ponto, e com estes dados foi feito um arquivo de correspondência

Após o georreferenciamento, foi feito o recorte da imagem através da opção Reformat/Window, extraindo apenas a área da bacia, conforme a Figura 2. 
Figura 2 - Imagem georreferenciada com composição das bandas 3, 4 e 5 do sensor "Thematic Mapper" do LANDSAT - 5 , na qual foi adicionada o limite da bacia hidrográfica.

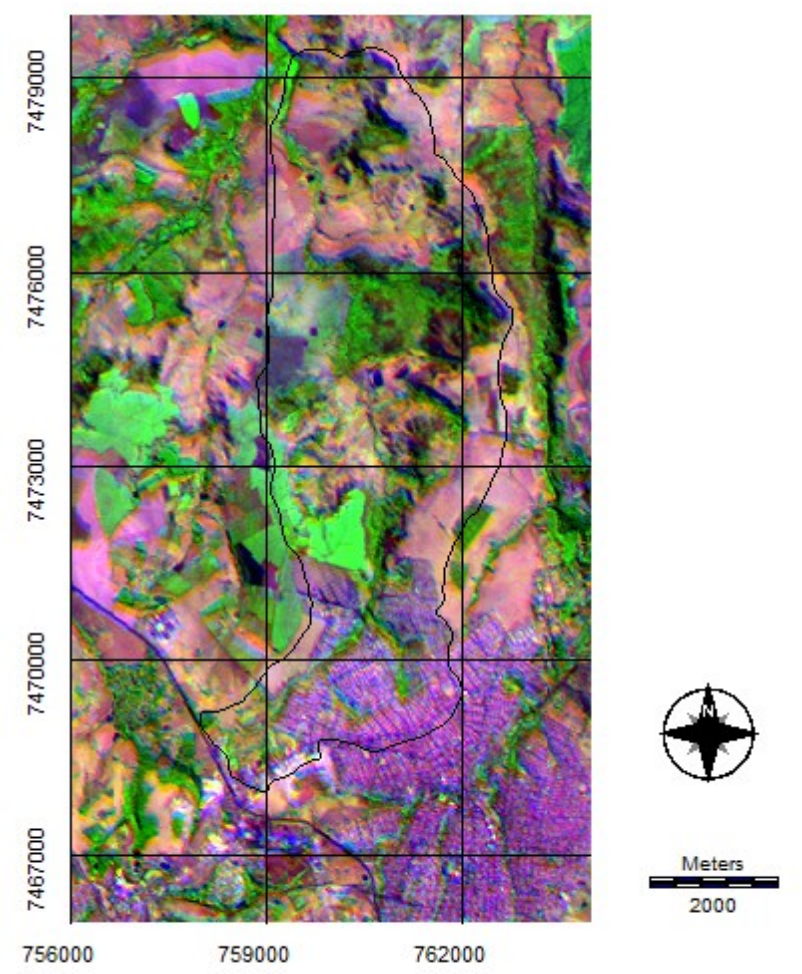

Em seguida, no software CartaLinx, através do comando File/lmage Conversion, buscou-se o arquivo georreferenciado, e salvou, em seguida, em File/New Coverage/Coverage Based Upon Bitmap, foi aberto o mesmo arquivo para começar o processo de delimitação dos elementos (limite, da rede de drenagem e das áreas de uso e cobertura). Para o limite e as áreas de uso e cobertura, foram criados polígonos, enquanto que para a rede de drenagem, linhas.

Quanto a elaboração dos polígonos de uso e cobertura, criou-se uma tabela, através do menu Tables/Add Fields, e em cada polígono colocou-se o número correspondente aos elementos (ex: Mata $=1$, Área Urbana $=2$, e assim sucessivamente). 
Posteriormente, exportou-se estes arquivos criados para o IDRISI. A tabela de uso e ocupação também foi exportada e transformada para raster. Através do comando Area do menu Database Query, pertencente ao módulo Analysis, foram determinadas as áreas e as porcentagens de cada uso.

\section{RESULTADOS}

Como resultado do estudo, pode-se verificar a identificação de 5 classes de uso, que compreendem mata, pastagem, cultura, reflorestamento, e área urbana, como observa-se na Figura 3.

Figura 3 - Usos e ocupações na bacia hidrográfica do Córrego São Caetano - Botucatu (SP).

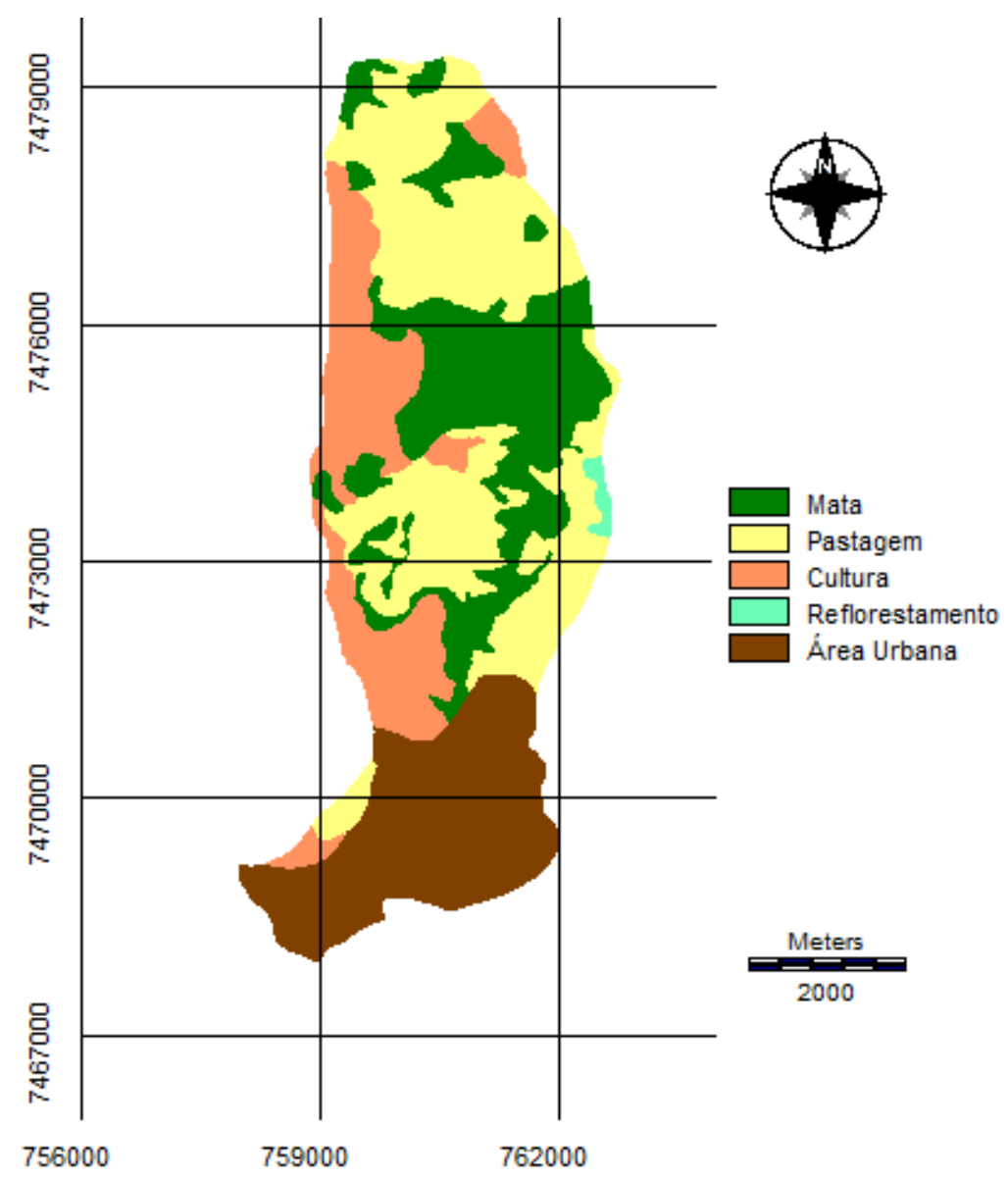


A interpretação das informações retiradas do mapa é feita de forma detalhada na Tabela 1, que contém os valores em hectares e porcentagens de cada classe de uso do solo e vegetação natural em relação à área total da bacia.

Tabela 1 - Áreas totais em hectares e porcentagens relativas às classes de uso na Bacia hidrográfica do Córrego São Caetano - Botucatu (SP).

\begin{tabular}{lll}
\hline Classes de uso da Terra & $\begin{array}{l}\text { Área } \\
\text { (ha) }\end{array}$ & \% \\
\hline Mata & 809,79 & 25 \\
Pastagem & 1117,94 & 34,51 \\
Cultura & 599,96 & 18,52 \\
Reflorestamento & 19,53 & 0,6 \\
Área Urbana & 692,19 & 21,37 \\
\hline Total & $\mathbf{3 2 3 9 , 4 1}$ & $\mathbf{1 0 0}$ \\
\hline
\end{tabular}

Os resultados obtidos (Figura 3 e Tabela 1) mostram que a bacia hidrográfica vem sendo ocupada por 809,79ha de mata; 1117,94ha de pastagens; 599,96ha por culturas; 19,53ha de reflorestamento e 692,19ha de área urbana.

A partir dos resultados, podemos afirmar que a área em estudo da bacia hidrográfica do Córrego São Caetano - Botucatu (SP) encontra-se preservada, sendo que $25 \%$ (809,79 ha) do total da área é composta por mata (vegetação natural), e o estabelecido por lei é de $20 \%$ do total de cada propriedade.

Vale enfatizar que o uso racional do solo deve ser baseado em atividades produtivas que considerem o potencial de terras para diferentes formas de uso, fundamentado no conhecimento das potencialidades e fragilidade dos ambientes, de forma a garantir a produção e reduzir os processos geradores de desequilíbrio ambiental, com base em tecnologias técnicas e ambientalmente apropriadas (GEBLER e PALHARES, 2007). 
Segundo Nardini (2009), o levantamento do uso do solo, em uma determinada região, torna-se um aspecto de interesse fundamental para a compreensão dos padrões de organização do espaço, já que o conhecimento das alterações ambientais, provocadas pela ação antrópica, possibilita uma visão dos problemas existentes e produz subsídios para gestão dos recursos naturais. É condição primordial para se programar uma política de uso racional do solo e de respeito à suscetibilidade e capacidade de suporte do meio ambiente aos impactos antrópicos, possibilitando o desenvolvimento socioeconômico sustentável.

\section{CONCLUSÃO}

A utilização de técnicas de sensoriamento remoto e de geoprocessamento foram bastante satisfatórias para a realização do presente trabalho, possibilitando a digitalização da base cartográfica, a elaboração de banco de dados, interpretação de satélite, a realização do cruzamento das informações e a produção do mapa final do uso do solo.

A grande expansão das atividades humanas sobre o meio ambiente mostra a importância da utilização de tecnologias em trabalhos agrícolas e ambientais.

Ferramentas tecnológicas, como os SIG (Sistemas de Informação Geográficas), são rápidos, eficazes e apresentam resultados confiáveis, auxiliando na busca pela sustentabilidade.

\section{REFERÊNCIAS}

ARGENTO, M. S. F.; CRUZ, C. B. M. Mapeamento geomorfológico. In: Geomorfologia: exercícios, técnicas e aplicações. Rio de Janeiro: Bertrand Brasil, 1996. Cap. 9, p.264-82.

BITTENCOURT, L.F.F.; BATISTA, G.T; CATELANI, C.S. Sensoriamento remoto aplicado ao estudo de ocupação de solo de mata ciliar do rio Paraíba do Sul no município de Caçapava. In: Anais do I Seminário de Sensoriamento Remoto e Geoprocessamento do Vale do Paraíba - GEOVAP; 2006; Taubaté, Brasil. UNITAU; 2006. p. 89-99.

BUCENE, L. C. Classificação de terras para irrigação utilizando um Sistema de Informações Geográficas em Botucatu - SP. Botucatu, 2002. 185 p. Dissertação (Mestrado em Agronomia/Irrigação e Drenagem) - Faculdade de Ciências Agronômicas, Universidade Estadual Paulista. 
GEBLER, L.; PALHARES, J. C. P. (Eds.) Gestão ambiental na agropecuária. Brasília: Embrapa Informação Tecnológica. 2007. 310p.

IBGE. INSTITUTO BRASILEIRO DE GEOGRAFIA E ESTATÍSTICA. Carta topográfica: folha de Botucatu - S SF-22-R-IV-3. Serviço gráfico do IBGE, 1969. Escala 1:50.000.

PELEGRIN, L. A. Técnicas de sensoriamento remoto e geoprocessamento aplicadas ao mapeamento do uso do solo: a Bacia do Rio Pará como um exemplo. 2001. 109p. Dissertação (Mestrado em Analise Espacial) - Pontifícia Universidade Católica de Minas Gerais, Belo Horizonte, MG. 2001.

PIRES, E. V. R.; SILVA, R. A.; IZIPPATO, F. J.; MIRANDOLA, P. H. Geprocessamento Aplicado a Análise do Uso e Ocupação da Terra para Fins de Planejamento Ambiental na Bacia Hidrográfica do Córrego Prata - Três Lagoas (MS). Revista Geonorte, Edição Especial, v.2, n.4, p.1528 - 1538, 2012.

ROCHA, C. H. B. Geoprocessamento: tecnologia transdisciplinar. Juiz de Fora: UFJF, 2007. 220 p.

SOUZA. I. F. de. Avaliação da Qualidade da Água do Córrego São Caetano na Área Urbana do Município de Botucatu- SP. Tese (Doutorado em Agronomia/Energia na Agricultura), Faculdade de Ciências Agronômicas, Universidade Estadual Paulista. 2012.

VETTORAZZI, C. A. Avaliação multicritérios, em ambiente SIG, na definição de áreas prioritárias à restauração florestal visando à conservação de recursos hídricos. 2006. p.151. Tese (Livre Docência em Geoprocessamento) - Escola Superior de Agricultura Luiz de Queiroz, Universidade de São Paulo, Piracicaba, 2006. 